\title{
Exploring Strategies That Influence Children's Physical Activity Self-Efficacy
}

\author{
Merav W. Efrat, California State University, USA
}

\begin{abstract}
Insufficient physical activity during the elementary school years has been associated with a number of health problems (Strong et al., 2006). During the school day, the recess period provides the greatest opportunity for children to engage in physical activity (Robert Wood Johnson, 2007). Nonetheless, most children spend the majority of their recess time in active. One strategy for increased physical activity during recess is to develop related interventions that reinforce physical activity from the school itself. While some research studies have identified modifiable factors, research suggests that a greater level of physical activity self-efficacy is the strongest predictor of increased physical activity among elementary-aged children (Coakley, \& White, 1992; Mulvihill, Rivers, \& Aggleton, 2000; Trost, Pate, Saunders, Ward, Dowda, \& Felton, 1997; Trost, 1999; Zakarian et al., 1994). Research suggests that strong influences on this age group include a teacher's encouragement and competent adult modeling (Chase 1995, Lirgg \& Feltz, 1991; Trost et al. 2003). The purpose of this study is to compare whether a teacher's encouragement alone and modeling by a competent adult alone influence children's recess time physical activity self-efficacy. In our study, this construct is measured through barrier self-efficacy (adult encouragement and other) and task self-efficacy (light, moderate, and vigorous). One hundred sixty-one students were assigned randomly to one of three groups: 1) modeling 2) encouragement, and 3) comparison. We collected pretreatment and posttreatment self-efficacy data as well. There was no significant interaction between the treatment and gender on self-efficacy. However, there was a significant main effect detected for treatment on adult encouragement barrier self-efficacy. Findings suggest that when teachers encourage children to be active, they may internalize the encouragement and become less dependent on external sources of encouragement to motivate them to be active during recess.
\end{abstract}

Keywords: Physical Activity; Self-Efficacy; Children; Recess

\section{INTRODUCTION}

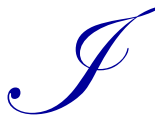

nsufficient physical activity during the elementary school years has been associated with health problems (Strong et al., 2005). Recommendations emphasize that children should accrue at least 30 to 60 minutes of daily moderate to vigorous physical activity (MVPA) (Corbin, Pangrazi, \& LeMasurier, 2004; Garber, Woods, \& Castilli, 2007). Despite this recommendation, evidence suggests that less than $50 \%$ of elementary school children actually engage in 30 to 60 minutes of MVPA (Troiano et al., 2007).

During any given school day, unstructured free time (i.e., recess) is the best chance for children to accrue physical activity (Robert Wood Johnson, 2007). Nonetheless, most children do not capitalize on recess time to reach current physical activity benchmarks (Ridgers, Stratton, \& Fairclough, 2005; Stratton, 1999, 2000, Efrat, 2011). Boys spend only $32.9 \%$, and girls spend only 25.3\%, of recess time in MVPA (Ridgers, Stratton, \& Fairclough, 2005).

Increasing the quantity of MVPA children accrue during recess is a promising approach to enabling more children to reach physical activity benchmarks (Efrat, 2013). One way to increase the amount of MVPA children accumulate during recess time is to design interventions that incorporate constructs associated with children's physical activity. Researchers have identified various modifiable factors associated with elementary school-aged children's physical activity. However, evidence suggests that the strongest predictor of elementary school-aged physical activity is physical activity self-efficacy (Coakley, \& White, 1992; Mulvihill, Rivers, \& Aggleton, 2000; Trost, Pate, Saunders, Ward, Dowda, \& Felton, 1997; Trost, 1999; Zakarian et al., 1994). Self-efficacy “is a judgment of one's capability to accomplish a certain level of performance" (Bandura, 1986, p. 391). 
Given the strong relationship between physical activity self-efficacy and children's physical activity, it is important that interventions aimed at promoting elementary school-aged children's physical activity during recess focus on enhancing physical activity self-efficacy. In the school context, determinants of children's physical activity selfefficacy include: peer models, competent adult models, and a parent's and teacher's encouragement (Chase 1995, Lirgg \& Feltz, 1991; Trost et. al, 2003). Children rely on adults more than peers for sources of information regarding physical activity self-efficacy, so it appears that a competent adult, compared to a peer model, may be a stronger determinant of children's physical activity self-efficacy (Horn, \& Weiss, 1991; Weiss, Ebbeck, Horn, 1997). During the school day, teachers have more contact with children than parents. Therefore, a teacher's encouragement may be more influential on recess time physical activity self-efficacy than parents' encouragement. Taken together, it seems that a competent adult's modeling and a teacher's encouragement are two strategies that may be most effective at enhancing children's physical activity self-efficacy, generally increasing physical activity during recess. Again, despite that a competent adult's modeling and a teacher's encouragement may influence physical activity self-efficacy, this has not been established in the context of recess. The purpose of this study is to compare if a teacher's encouragement alone and modeling by a competent adult alone similarly impact children's recess time physical activity self-efficacy.

\section{METHODS}

One hundred sixty-one $4^{\text {th }}$ graders were recruited from three elementary schools and randomized in three groups: modeling, encouragement, and comparison. Participant demographics by group are in Table 1 (Efrat, 2016).

Table 1. Participants' Demographic Information by Treatment Group

\begin{tabular}{l|c|c|c|c}
\hline & & $\begin{array}{c}\text { Encouragement } \\
\text { Number (\%) }\end{array}$ & $\begin{array}{c}\text { Comparison } \\
\text { Number (\%) }\end{array}$ & $\begin{array}{c}\text { Modeling } \\
\text { Number (\%) }\end{array}$ \\
\hline Total Number of Participants & & 59 & 51 & 51 \\
\hline Gender: & Male & $22(37.3 \%)$ & $25(49 \%)$ & $22(43.1 \%)$ \\
\hline & Female & $37(62.7 \%)$ & $26(51 \%)$ & $29(56.9 \%)$ \\
\hline Age: & & $14(23.7 \%)$ & $5(9.8 \%)$ & $6(11.8 \%)$ \\
\hline & 9 & $43(72.9 \%)$ & $43(84.3 \%)$ & $43(84.3 \%)$ \\
\hline & 10 & $2(3.4 \%)$ & $3(5.9 \%)$ & $2(3.9 \%)$ \\
\hline Ethnicity: & White & $18(30.5 \%)$ & $19(19.6 \%)$ & $17(33.3 \%)$ \\
\hline & Latino & $28(47.5 \%)$ & $25(49 \%)$ & $24(47.1 \%)$ \\
\hline & African American & $7(11.9 \%)$ & $7(13.7 \%)$ & $4(7.8 \%)$ \\
\hline & Asian & $5(8.5 \%)$ & $5(9.8 \%)$ & $3(5.9 \%)$ \\
\hline & Filipino or Pacific & $0(0 \%)$ & $2(3.9 \%)$ & $1(2 \%)$ \\
\hline & Islander & $1(1.7 \%)$ & $1(2 \%)$ & $0(0 \%)$ \\
\hline
\end{tabular}

\section{Recess Time Physical Activity Self-Efficacy Instrument}

The recess time physical activity self-efficacy baseline data described below is data collected for a study which was previously published (Efrat, 2016). The investigator utilized Efrat's (2016) Recess Time Physical Activity SelfEfficacy Scale (RTPASES) to measure recess time physical activity self-efficacy. Efrat's RTPASES was adapted from prior investigator's physical activity self-efficacy scales (Annesi et al., 2005, Foley et al., 2008). The RTPASES measured three types of task self-efficacy (vigorous, moderate, and light) and two types of physical activity barrier self-efficacy (adult encouragement barrier self-efficacy and other barrier self-efficacy). Task self-efficacy is a child's level of confidence to engage in various levels of physical activity intensity (i.e. vigorous, moderate or light) during recess. Adult encouragement barrier self-efficacy is a child's confidence in their ability to engage in physical activity during recess even if an adult does not encourage them to do so. Other barrier self-efficacy involves a child's 
confidence in their ability to overcome other personal, social and environmental barriers linked to physical activity. The RTPASES utilized a 5-point Likert Scale ranging from 1 (not at all confident) to 5 (definitely confident) (Efrat, 2016).

\section{Procedures}

Before collecting data, the investigator obtained Institutional Review Board approval from the University of Southern California Office for the Protection of Research Subjects and the Los Angeles Unified School District Committee for External Research Review. The investigator required a signed child assent form and signed parental consent form for participation in the study. While administering the RTPASES, the investigator and her research assistants facilitated a few activities to increase participants' understanding of survey items regarding self-efficacy. Previous research has found that presenting children with concrete examples of sedentary activities and various physical activity intensities improves their understanding of the definition of physical activity (Trost et al., 2000). Moreover, Bandura (2006) indicates that presenting children with concrete examples of the scale that will be used to assess their self-efficacy may reduce children's misconceptions connected to values used on a self-efficacy scale.

To improve participants' comprehension of the concept of physical activity, the investigator provided a verbal description of various physical activities children can participate in during recess, as well as sedentary activities children frequently participate in during recess. To increase participants' comprehension of the concept of vigorous, moderate and light physical activity, the investigator read participants a definition of each physical activity intensity level and encouraged them to engage in a brief bout of activity at that particular intensity. For instance, after reading a definition of vigorous physical activity, the investigator had participants sprint a short distance (Efrat, 2016).

Additionally, by using chalk, the investigator and her research assistants marked the playground area with five lines at an increasingly farther distance from each other. Using the same scale descriptors from the RTPASES, (e.g., not at all confident, somewhat confident, definitely confident), participants were asked to rate their level of confidence in their ability to jump to each of the five distances. After they had completed this task, the investigator verified that the participant understood the scale descriptors, which would be used to assess their level of confidence in the RTPASES. Following these activities, the investigator and her research assistants implemented the RTPASES. To increase participants' comprehension of each survey item, the investigator read each questions to all study participants (Efrat, 2016).

\section{Treatments}

The treatments used in this study (described below) were part of a previously published study (Efrat, 2013), which included a teacher's encouragement, modeling of recess time games by a competent adult, and no treatment. The encouragement treatment involved classroom teachers providing students with a brief message, encouraging them to make an active choice to engage in MVPA during recess. This message was delivered daily over a 6-week period before morning recess and lunch time recess. In advance of the encouragement treatment, teachers facilitated a discussion of the benefits of MVPA with students. The modeling treatment entailed six 50-minute sessions implemented during students' regularly scheduled psychomotor instruction. In the Los Angeles Unified School District, psychomotor instruction is physical activity instruction implemented by someone who does not hold either a multiple subject credential or a single subject credential in Physical Education. The investigator and her research assistants taught participants a total of eight active recess time games. Using her expertise in physical activity, the investigator selected and slightly modified games to increase potential MVPA a child could accumulate while playing a particular game. The first session included a brief educational part which entailed: a program overview, education on the difference between light, moderate, and vigorous physical activity, a description of the benefits of engaging in MVPA during recess, and a review of playground conflict resolution skills. Research indicates that conflicts between children frequently occur on the playground (Hartup \& Laursen, 1993). When children learn conflict resolution skills, they are likely to productively manage these inevitable conflicts, resulting in continued engagement in active play (Efrat, 2013). 


\section{Data Analysis}

All data were analyzed using SPSS for Windows (17.0). Descriptive statistics for self-efficacy were computed. A series of $2 \times 3$ one-way Analysis of Variance (ANOVA) were run to examine the main effect of gender on self-efficacy before treatment. To determine the influence of the treatments on self-efficacy, a series of $2 \times 3$ one-way Analysis of Covariance (ANCOVA) was run, adjusting for gender with a pre-test score as a covariate.

\section{RESULTS}

A series of one-way ANOVAs determined that with pretreatment, there was no significant self-efficacy mean difference between gender groups. A series of 2 (gender) x 3 (group) ANCOVAs with pretreatment scores as covariates determined there was no significant interaction between treatment and gender on self-efficacy. Further, we detected a significant main effect for treatment on post-adult encouragement barrier self-efficacy.

Results indicated that a teacher's encouragement, compared to modeling, was significantly more effective at influencing a child's confidence in their ability to be less dependent on an adult's encouragement to prompt them to be active during recess, $p=.001$. No treatment, compared to modeling, was more effective at influencing a child's confidence in their ability to be less dependent on an adult's encouragement to prompt them to be active during recess, $p=006$. Figure 1 displays the significant main effects of treatment on adult encouragement physical activity selfefficacy.

Figure 1. Main Effect of Treatment on Adult Encouragement Barrier Self-Efficacy

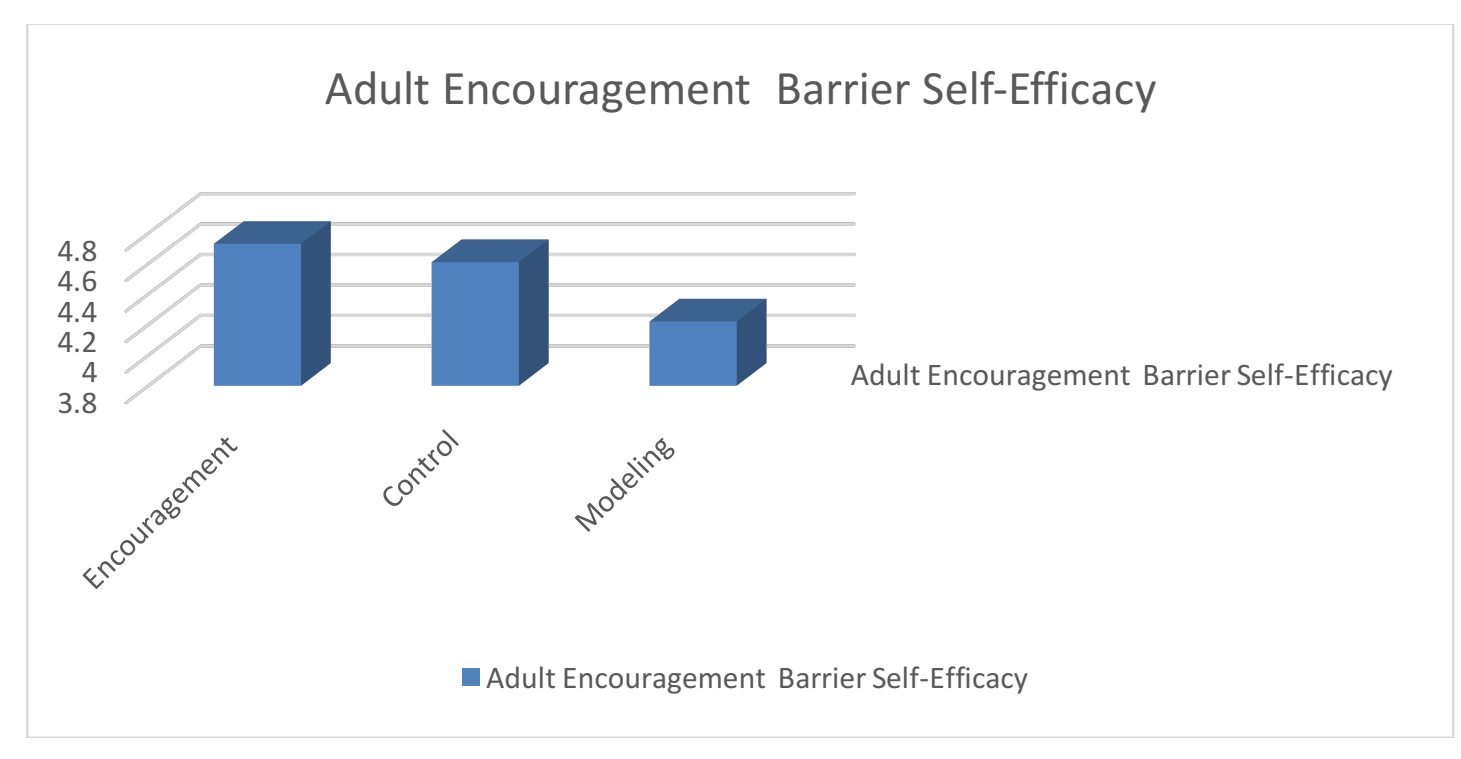

\section{DISCUSSION}

\section{The Influence of a Teacher's Encouragement on Physical Activity Self-Efficacy}

This study found that a teacher's encouragement was more effective than modeling at influencing adult encouragement barrier self-efficacy. The teacher's encouragement groups' adjusted post-adult encouragement barrier self-efficacy mean scores were significantly higher than the modeling groups. These findings may be the result of an interaction between a teacher's encouragement and a child's normal developmental processes. Perhaps when a child receives a small dose of a teacher's encouragement to be active, it speeds up the typically observed developmental processes which result in adults having less influence on older children's perceptions of their physical abilities (Horn \&Weiss, 1991; Weiss et al., 1997). 


\section{The Influence of Modeling on Physical Activity Self-Efficacy}

This study indicates that modeling was less effective than a teacher's encouragement at influencing children's selfefficacy. Prior research found that competent adult models are effective at increasing children's physical activity selfefficacy (Lirgg \& Feltz, 1991; McAuley, 1985). This prior research involved a competent adult who modeled a specific physical activity skill in a structured physical activity context and then the investigators measured self-efficacy in the same context. In contrast, this study entailed a competent adult who modeled physical activity skills (recess games and conflict resolution skills) in a structured physical activity environment (supervised psychomotor instruction) yet the investigator measured self-efficacy in another context (recess time). Perhaps if modeling took place during recess time or the investigator measured self-efficacy in the context of psycho-motor instruction it would have resulted in a more significant increase in physical activity self-efficacy.

Further, it appears that the skills modeled in the modeling treatment did not include all of the skills needed to make an active choice to engage in physical activity in unstructured environments. For instance, in unstructured environments such as recess, children must be able to initiate among their peers a request to play a particular game and get the equipment needed to play the particular game, which may explain why posttreatment participants in the modeling group did not have significant gains in self-efficacy. These findings suggest that modeling games and conflict resolution skills are not enough to increase children's confidence in their ability to overcome various barriers associated with making the active choice to engage in physical activity during recess. Future research may examine the influence of modeling during recess that includes the modeling of games, conflict resolution skills, and the skills a child would need to make the active choice to initiate and maintain play with one's peers during recess time (Efrat, 2013).

This study has serval limitations. The investigator was unable to control for all confounding variables at the school and teacher level that could potentially impact physical activity self-efficacy. Although the investigator selected three schools with similar characteristics, it was not possible to control all of the confounding variables. Those variables include classroom teachers and yard aides' enthusiasm for physical activity and teachers' recess time practices (e.g., encouraging children to complete classroom or homework assignments during recess). Conducting this study at one school rather than at three would have eliminated the school level confounding variables. However, it could also have resulted in contaminated results (Efrat, 2013). Prior research on the impact of a school-based intervention at one site found that cross-contamination occurs when children from different classrooms play together during recess, making it difficult to detect differences between treatment and comparison groups (Kulinna, Cothran, Brusseau, \& TudorLocke, 2008). Future research could explore a nested design analysis to accommodate potential school and classroom differences (Goldstein, 1995).

Along those same lines, one confounding variable that is especially important to note relates to school recess time practices. When schools were contacted to participate in this study, to the investigator's knowledge, none of the schools had recess time practices in place that might have influenced self-efficacy. However, before study implementation, a new recess time practice was implemented at the encouragement school which may have contributed to the influence observed on self-efficacy. Following the first 10 minutes of recess, yard aides at this school asked students to get up from the cafeteria tables and go play. This practice was in place for baseline data collection, but it is unclear how it may have interacted with the teachers' encouragement. It is possible that encouragement alone may not have yielded the same significant results. Last, since this study occurred at a Southern California suburban elementary school, results may not generalize to rural or urban elementary schools.

\section{CONCLUSIONS}

The following is a discussion of recommendations for future research aimed at understanding how to increase elementary school-aged children's recess time physical activity self-efficacy. Research indicates that there is a positive association between children's physical activity and physical activity self-efficacy. Findings from this study show that participants in the encouragement group, compared to the modeling group, had significantly higher postadult encouragement barrier self-efficacy. Taken together, it seems that adult encouragement barrier self-efficacy may play some role in influencing children's recess-time physical activity. Future research should further explore whether increases in adult encouragement barrier self-efficacy correspond to increases in the amount of physical 
activity children accrue during recess. This study provides new evidence that a teacher's encouragement can influence children's recess time physical activity self-efficacy. Future research might explore the impact of encouragement of other adults at the school (e.g., principals, yard aides, coaches,) and a teacher's encouragement on recess time physical activity self-efficacy.

Given that physical activity is associated with substantial health and academic benefits, it is important to establish evidence-based strategies to increase it during recess. In light of evidence indicating that there is a strong relationship between children's physical activity levels and physical activity self-efficacy, this study attempted to explore the efficacy of two strategies that may influence children's physical activity self-efficacy. This study provides evidence that a teacher's encouragement is more effective than modeling of active recess time games at influencing children's confidence to engage in physical activity. These results suggest that when children are encouraged to be active, they may internalize the encouragement and become less reliant on external encouragement to motivate them to be active.

\section{ACKNOWLEDGEMENTS}

The author would like to thank the principals, teachers, and children at the schools that participated in the study. The author would also like to thank Anya Hobley and Keylaundra McClelland who helped with the data collection and Thaddeus S. Molnar, Henry Maldonado and Jason who assisted with implementing the modeling intervention. In addition, the author would like to thank Younjoo Oh for his assistance with data analysis

\section{AUTHOR BIOGRAPHY}

Dr. Merav Efrat is an Associate Professor in the Department of Health Sciences at California State University, Northridge. She has over 10 years of professional work experience as a Health Educator and International Board Certified Lactation Consultant. Her research focuses on developing and evaluating interventions that reduce childhood obesity, particularly among disadvantaged communities. Specifically, in an attempt to reduce the prevalence of childhood obesity, she is interested in examining the efficacy of interventions that can be used to promote physical activity among elementary school-age children, as well as to promote six months exclusive breastfeeding.

\section{REFERENCES}

Annesi, J. J. (2006). Relations of physical self-concept and self-efficacy with frequency of voluntary physical activity in preadolescents: Implications for after-school care programming [Electronic version]. Journal of Psychosomatic Research, 61(4), 515-520.

Annesi, J. J., Faignenbaum, A. D., Wesscott, W. L., Smith, A. E., Unruh, J. L., \& Hamilton, F. G. (2007). Effects of the youth fit for life protocol on physiological mood, self-appraisal, and voluntary physical activity changes in African American preadolescents: Contrasting after-school care [Electronic version]. International Journal of Clinical and Health Psychology, 7(3), 641-659.

Annesi, J. J., Westcott, W. L., Faigenbaum, A. D., \& Unruh, J. L. (2005). Effects of a 12-week physical activity protocol delivered by YMCA after-school counselors (youth fit for life) on fitness and self-efficacy changes in 5-12 year old boys and girls [Electronic version]. Research Quarterly for Exercise and Sport, 76(4), 468-469.

Bandura, A. (1986). Social foundations of thought and action: A social cognitive theory. Englewood Cliffs, NJ: Prentice-Hall, Inc.

Bandura, A. (2006). Guide for constructing self-efficacy scales. In F. Pajares \& T. Urdan (Eds.). Self-efficacy beliefs of adolescents (pp. 307-337). Charlotte, NC: Information Age Publishing.

Centers for Disease Control and Prevention (2005). Quickstats: Prevalence of overweight among children and teenagers, by age group and selected period, 1963-2002 [Electronic version]. Morbidity and Mortality Weekly Report, 54 (8), 203.

Chase, M.A. (1995). Children's sources of self-efficacy accuracy of appraisal and motivation in sport skills and physical activities (Doctoral dissertation, Michigan State University, 1995). (UMI No. 9605845).

Chase, M.A. (2001). Children's self-efficacy: Motivational intentions and attributions in physical education and sports [Electronic version]. Research Quarterly for Exercise and Sport, 72(1), 47-54.

Coakle, J., \& White, A. (1992). Making decisions: gender and sport participation among British adolescents [Electronic version]. Sociology of Sport Journal, 9(1), 20-35.

Corbin, C. B., Pangrazi, R. P., \& Le Masurier, G. C. (2004). Physical activity forchildren: Current patterns and guidelines [Electronic version]. President's Council on Physical Fitness and Sports Research Digest, 5(2), 1-8. 
Davison, K. K., Cutting, T. M., \& Birch, L. L. (2003). Parents activity-related parenting practices predict girls' physical activity [Electronic version]. Medicine Science in Sports \& Exercise, 35(9), 1589-1595.

Efrat, M.W. (2013) Efrat, M.W (April 2013). Exploring effective strategies for increasing the amount of moderate to vigorous physical activity children accumulate during recess: A quasi-experimental intervention study. The Journal of School Health, 83(4), 265- 272.

Efrat, M.W. (October 2016). Understanding Factors Associated With Children's Motivation To Engage In Recess-Time Physical Activity, Contemporary Issues in Education Research. 9(2), 77-86.

Foley, L., Prapavessis, H., Maddison, R., Burke, S., McGowan, E., \& Gillanders, L. (2008). Predicting physical activity intention and behavior in school-age children [Electronic version]. Pediatric Exercise Science, 20(3), 342-356.

Garber, K. C., Woods, A. M. \& Castilli, D. M. (2007). Chapter 1: Setting the stage-research into physical activity relationships and children's progress toward achievement of the national standards [Electronic version]. Journal of Teaching Physical Education, 26, 338-349.

Goldstein, H. (1995). Multilevel statistical models ( $2^{\text {nd }}$ ed.). London: Arnold.

Hertz, R., \& Marshall, N. L. (Eds.). (2001). Working families the transformation of the American home. Los Angeles: University of California Press.

Horn, T. S. \& Weiss, M. R. (1991). A developmental analysis of children's self-ability judgments in the physical domain [Electronic version]. Pediatric Exercise Science, 3, 310-326.

Kulinna, P. H., Cothran, D. J., Brusseau, T., \& Tudor- Locke, C. (2008). Increasing physical activity behaviors through a comprehensive school change effort. Paper presented at the AARE 2008 International Education Research Conference, Brisbane, Australia.

Lee, A. M., Hall, E. G., \& Carter, J. A. (1983). Age and sex differences in expectancy for success among American children [Electronic version]. The Journal of Psychology, 113, 35-39.

Lirgg, C.D. \& Feltz, D.L. (1991). Teacher versus peer models revisited: Effects on motor performance self-efficacy [Electronic version]. Research Quarterly for Exercise and Sport, 62 (2), 217-224.

McAuley, E. (1985). Modeling and self-efficacy: A test of Bandura's model [electronic version]. Journal of Sport Psychology, 7(3), 283-295.

Mulvihill, C., Rivers, K., Aggleton, P. (2000) A qualitative study investigating the views of primary-age children and parents on physical activity [Electronic version]. The Health Education Journal, 59(2), 166-179.

Norton, D. E. (2003). Eating and exercise behaviors in preadolescents: Parental influence? Unpublished Ph.D., University of California, San Francisco.

Pate R. R., Baranowski T., Dowda M., \& Trost S. G. (1996). Tracking of physical activity in young children [Electronic version]. Medicine Science in Sports and Exercise, 28, 92-6.

Paxson, C., Donahue E., Orleans, T., \& Grisso, J. A. (2006) Introducing the issue [Electronic version]. The Future of Children, 16(1), 3-17.

Ryan, G. J. \& Dzewaltowski, D. A. (2002). Comparing the relationship between different types of self-efficacy in physical activity in youth [Electronic version]. Health Education \& Behavior, 29(4) 491-504.

Ridgers, N. D., Stratton, G., \& Fairclough, S. J. (2005). Assessing physical activity during recess using accelerometry [Electronic version]. Preventive Medicine, 41,102-107.

Robert Wood Johnson Foundation (2007). Recess rules: Why the undervalued playtime may be America's best investment for healthy kids and healthy schools.

Sallis, J. F., Alcaraz, J. E., McKenzie, T. L., Hovell, M. F., Kolody, B., \& Nader, P. R. (1992). Parental behavior in relation to physical activity and fitness in 9 year old children. Sports Medicine, 146, 1383-1388.

Sallis, J. F., Alcaraz, J. E., McKenzie, T. L., Melbourne, H. F \& Hovell, M. F. (1999). Predicators of change in children's physical activity over 20 months variations by gender and level of adiposity [Electronic version]. American Journal Preventive Medicine, 16(3), 222-229.

Sallis, J. F., Prochaska, J. J., \& Taylor, W. C. (2000). A review of correlates of physical activity of children and adolescents [Electronic version]. Medicine Science Sports Exercise, 32(5), 93-975.

Sharma, M., Wagner, D. I., \& Wilkerson, J. (2005). Predicting childhood obesity prevention behaviors using social cognitive theory [Electronic version]. International Quarterly of Community Health Education, 24(3), 191-203.

Stratton G. (1999). A preliminary study of children's physical activity in one urban primary school playground: differences by sex and season [Electronic version]. Journal of Sport Pedagogy, 5, 71-81.

Stratton G. (2000). Promoting children's physical activity in primary school: An intervention study using playground markings [Electronic version]. Ergonomics, 43(10), 1538-1546.

Strong, W. B., Malina, R. M., Blimkie, C. J. R., Daniels, S. R., Dishman, R. K., Gutin, B. G., et al. (2005). Evidence based physical activity for school age youth [Electronic version]. Journal of Pediatrics, 146, 732-737

Troiano, R., P., Berrigan, D., Dood, K. W., Masse, L. C, Tilert, T., \& McDowell, M. (2007). Physical Activity in the United States measured by accelerometer [Electronic version]. Medicine \& Science in Sports \& Exercise, 40(1), 181-188

Trost, S. G., Pate, R. R., Saunders, R., Ward, D. S., Dowda, M., \& Felton, G. (1997). A perspective study of the determinants of physical activity in rural fifth grade children [Electronic version]. Preventive Medicine, 26, 257-263

Trost, S.G., Pate, R. R., Ward, D. S., Saunders, R., \& Riner, W. (1999a). Correlates of objectively measured physical activity in 
preadolscent youth [Electronic version]. American Journal Preventive Medicine, 17(2), 120- 126.

Trost, S. G., Pate, R.R., Ward, D.S., Saunders, R., \& Riner, W. (1999b) Determinants of physical activity in active and lowactive, sixth grade African American youth [Electronic version]. Journal of School Health, 69(1), 29-34.

Trost, S. G., Sallis, J. F., Pate, R. R., Freedson, P. S., Taylor, W. C., \& Dowda, M. (2003). Evaluating a model of parental influence on youth activity [Electronic version]. American Journal of Preventive Medicine, 25(4), 277-282.

Weiner, B. (1990). History of motivational research in education. Journal of Educational Psychology, 82(4), 616-622.

Weiss, M. R., Ebbeck, V., \& Horn, T.S. (1997). Children's self-perceptions and sources of physical competence information: a cluster analysis [Electronic version]. Journal of Sport \& Exercise Psychology, 19, 52-70.

Zakarian, J. M., Hovell, M. F., Hofstetter, C. R., Sallis, J. K., \& Keating K. J. (1994). Correlates of vigorous exercise in predominantly low SES and minority high school population [Electronic version]. Preventive Medicine, 23, 314-321. 